\title{
Por una lectura de los clásicos en la adolescencia'
}

\author{
Towards Reading the Classics in Adolescence \\ CLARA AYUSO COLLANTES \\ Universidad Pontificia de Comillas \\ España \\ claraa.collantes@gmail.com
}

(Recibido: OI-O7-2OI8; aceptado: $5_{5}^{-O I-2 O 2 O)}$

Resumen. En el contexto de una sociedad que tiene a menos la vinculación con el pasado y la herencia de las humanidades, se defiende en este trabajo la lectura gustosa de los clásicos -bien en fragmentos seleccionados, bien en adaptaciones de obras enteras- en la clase de literatura con adolescentes. Se aducen una serie de razones tanto pedagógicas como antropológicas y culturales para ello y se postula que es el profesor quien debe elegir los textos más adecuados para esas edades y quien debe estimular y guiar a los alumnos en la lectura, para que saquen el mayor gusto y provecho personal. Para que el presente trabajo no quede en mera exposición teórica, se añaden algunos ejemplos prácticos de cómo presentar a los alumnos textos concretos de la literatura medieval e implicarlos en su lectura e interpretación. Ello se hace desde una aceptación amplia y variada del canon de lecturas $y$ teniendo en cuenta las funciones que la literatura ha de cumplir en el currículum de la enseñanza secundaria.

Palabras clave: clásicos; lectura; canon; adaptaciones; adolescencia.
Abstract. In a society that underestimates its link with the past and the Humanities' heritage, in this article we defend the enjoyable reading of Classical texts - either selected passages or adaptations of whole books - during Literature classes with teenagers. We argue through various reasons, both pedagogical, anthropological and cultural for this purpose, and we postulate that the teacher is the one who has to choose the most suitable texts for those ages. The teacher also has to encourage and guide students in their reading, so that they make the most of it, both for their enjoyment and personal benefit. So that this paper is not a simple academic exposition, we will add some practical examples about presenting specific medieval texts to our students in order to engage them in the reading and its representation. This will be approached from an extensive and inclusive perspective of the reading canon, and the functions that literature must fulfill in the secondary education curriculum will be also kept in mind.

Keywords: classical texts; reading; canon; adaptations; adolescence.

\footnotetext{
${ }^{\text {I }}$ Para citar este artículo: Ayuso Collantes, Clara (2020). Por una lectura de los clásicos en la adolescencia. Álabe 22 . [www.revistaalabe.com]

DOI: IO.I5645/Alabe2020.22.I
} 
No corren buenos tiempos para la literatura. Sobre todo, en la enseñanza. Los profesores de Secundaria se lamentan de lo poco motivados que están los alumnos para encarar el estudio de la literatura en la edad adolescente. Los nombres gloriosos de nuestra literatura les dicen poco, y sus textos, cuando les gustan, se suelen perder por lo general entre otras propuestas de su ocio que les satisfacen y les enganchan más: canciones de éxito, ídolos deportivos, la moda y las marcas, el manejo del móvil... La literatura raramente entra en su horizonte de expectativas. Aún habiendo sido buenos lectores de pequeños, ahora empieza a pesarles el tiempo de lectura.

Además, por ley, ellos han de empezar el estudio metódico de la historia literaria en el tercer curso de la ESO por el principio; es decir, por la Edad Media y los Siglos de Oro, con un lenguaje y una mentalidad lejanos y desmotivadores. Enfrentarse a estas edades tempranas con contenidos culturales que exigen atención y dedicación es todo un reto. Una tarea ardua que, sin embargo, merece la pena abordar de cara a su educación. Porque el valor formativo de la literatura sigue intacto, aunque la nebulosa de nuestro tiempo trate de borrar las humanidades por lo mal que se avienen con la banalidad de la vida moderna y el pragmatismo de los deseos a corto plazo.

\section{Los clásicos: tradición y actualidad}

La crisis de las humanidades conlleva el abandono o escasa frecuentación de los autores clásicos. Esta crisis de la tradición humanística europea no sucede solo en la enseñanza, es una crisis generalizada que tiene raíces profundas. El fenómeno escolar tiene que ver con el cambio de valores culturales acaecidos de unas décadas acá en la sociedad actual, la que se ha dado en llamar sociedad posmoderna o postindustrial.

El posmodernismo ha supuesto un cambio radical en la naturaleza del saber, ha cambiado contenidos y formas de investigación y atención a la realidad, ha puesto en entredicho los saberes tradicionales desde un relativismo que suspende en la duda cuanto tuvo valor y sirvió de fundamento en la modernidad. En un libro reciente, el profesor italiano Ordine (2OI7) se lamenta de que los clásicos no ocupen ya el lugar que en otro tiempo tenían en la formación del ciudadano medio europeo, así como el desprestigio en que se ha sumido su estudio en la escuela y en la universidad, y defiende una recuperación impostergable, pues son necesarios para la vida. Y sentencia: "Si no salvamos los clásicos y la escuela, la escuela y los clásicos no podrán salvarnos” (p. II).

La explicación de su postergación, ya está dicho, hay que buscarla en el relativismo y la mediocridad de un mundo actual que relega la exquisitez y la excelencia porque prefiere halagar a la masa con entretenimientos más sensoriales y efímeramente placenteros. Porque un clásico no es sino un modelo, alguien cuya obra adquiere valor en el tiempo por su excelencia. Ese saber sobrevivir a las corrientes del gusto y estar siempre abierto a la atención y al interés de los lectores de las distintas épocas es lo que hace que un clásico sea tenido como tal. Ideas estas que sostienen unánimemente quienes reco- 
miendan su lectura y su difusión en la escuela y en la sociedad (Calvino, I997; Ordine, 2OI7).

Hoy no puede dejar de mencionarse a Italo Calvino y su celebrado Por quéleer a los clásicos (I99I), en cuyo capítulo inicial aduce catorce razones para seguir leyendo a estos autores consagrados, alguna de las cuales nunca deja de ser citada por quienes tratan el tema. Aunque todas las resume en una última, contundente y definitiva: "leer a los clásicos es mejor que no leer a los clásicos (I997: 20).

En la enseñanza secundaria el problema del canon no se plantea en términos polémicos, pero no ha dejado de existir desde los años noventa. Como rechazo a la enseñanza elitista de la literatura en el franquismo, basada en la excelencia de los clásicos, en los ochenta del pasado siglo empezaron a oírse voces reivindicando para los alumnos otras lecturas más actuales y cercanas a sus intereses.

Las editoriales escolares, aunque no han dejado de lanzar buenas y actualizadas ediciones de los clásicos, adaptadas o no, han descubierto un filón en la literatura de temas específicamente juveniles, ya sean traducciones u originales en castellano. Ello ha dado origen a un canon "mixto" en el que los clásicos de todos los tiempos y lenguas comparten catálogo con libros de rabiosa actualidad y especialmente escritos para suscitar el interés de los jóvenes. Todo ello con el visto bueno de los especialistas y profesores de instituto.

El diagnóstico que hacen en sus obras Lipovetsky (I986 y ı989) o Bauman (2007) nos sirve muy bien para entender la crisis de la enseñanza y, en ella de las humanidades y de la literatura, lo que supone hacer balance de aquello que se ha perdido y de lo que todavía se puede recuperar. Solo desde un certero diagnóstico los problemas pueden encararse pensando en las estrategias más oportunas para ello. No se trata de querer repetir el pasado, porque el presente tiene otros afanes y crea otras expectativas en los adolescentes, pero sí que ayuda a buscar otros ángulos y nuevas posibilidades que permitan presentar y recrear los clásicos.

Es preciso reforzar con la lectura de los autores excelentes de otro tiempo valores que han menguado o se están perdiendo, tal como propugnan los estudiosos que con más ahínco anhelan su presencia en la sociedad y en las aulas. Al hilo de las lecturas hechas en los autores elegidos, citaremos algunas razones:

I. Los clásicos son una necesidad social. Navarro (ı996, 20I3) García Gual (I998) y Ordine (2OI7), por ejemplo, alientan vivamente su presencia y su difusión como valladar contra el antihumanismo de nuestra época, lo que redundará en beneficio de la propia sociedad tan sumida en la mediocridad como huérfana de excelencia.

2. Frente a los que dicen que un clásico pertenece al pasado y poco tiene que aportar al hombre de la calle o al adolescente de la sociedad postindustrial, está el argumento de la perenne actualidad de un clásico. "Es clásico lo que persiste como ruido de fondo incluso allí donde la actualidad más incompatible se impone" (Calvino, r997: r9). Rosa Navarro añade que no hay mejor demostración de 
la actualidad de un clásico que la pervivencia a través de los años y las diversas interpretaciones que de él se han ido haciendo. Pone como ejemplo a Cervantes, con la diversidad de lecturas que de él se han hecho en los distintos periodos de la historia: barroco, romanticismo, noventayocho, etc. (20I3). No deja de ser otra forma de expresar la feliz acuñación de Calvino: “Un clásico es un libro que nunca termina de decir lo que tiene que decir (1997: I5).

3. Un clásico encierra en sí un gran valor por ser especialmente representativo de un pueblo o una comunidad nacional y una lengua. Para Eliot (I992: 55-73), el poeta y ensayista norteamericano nacionalizado inglés, un clásico es el producto de la madurez de su lengua y su cultura. Efectivamente, hay obras que son el legado valioso de un pueblo, pues nadie como ellos ha sabido representar la forma de ser y vivir y mirar el mundo de esa comunidad. En este sentido, El Quïote, que nació en la plenitud de la cultura española, encarnaría como ningún otro libro nacional la idiosincrasia española a través del tiempo, así como ha sido el factor fundamental de unidad del hispanismo en la lengua común (Pozuelo, 2009).

4. Un clásico importa por sus valores pedagógicos. Por eso hay que leerlos, porque son "capital cultural” de una lengua o nación (García Gual, I998: 36). Son modelos que enriquecen a la comunidad y, como dice Rosa Navarro (г996): "han dado nuevas claridades al mundo, nueva belleza a la palabra” (p. 7). Son referentes insoslayables de una lengua y una cultura nacionales y es a la escuela a la que le corresponde salvaguardar y transmitir ese legado. No han faltado voces advirtiendo que una inmersión prematura en la literatura clásica no solo sería inconveniente sino contraproducente (Colomer, I998). Por eso, lo que hoy se debate no es que deban ser postergados cuanto más mejor, sino cómo acercarlos con garantías a ciertas edades de modo que interesen a los alumnos porque entran dentro de las expectativas de su edad, de su capacidad cognitiva y de su apertura imaginativa (Navarro, 20I3 y 2OI6). El acercamiento ha de ser gradual y placentero, siempre placentero, lo cual no quiere decir que este no ofrezca sus puntos de reflexión y de aplicación práctica en su conocimiento de lo real y en su horizonte vital. (Reyzábal y Tenorio, I992; Jover, 2007). El mensaje de los clásicos destaca, precisamente, por ser válido y reseñable en cualquier tiempo, y de eso se trata, de que, en mayor o menor grado, conecten con la experiencia lectora y ayuden a discernir en sus voces de ayer la actualidad de hoy (Calvino, 1997).

5. Es modelo lingüístico y ejemplo fehaciente de hasta donde puede llegar la capacidad creativa de un idioma, hecha por su hablantes a lo largo del tiempo y plasmada por la genialidad del arte. La prevención que existe en algunos corros educativos para ponerlos a la vista y al alcance de los lectores más jóvenes por lo que llaman su dificultad, debiera desaparecer. Se arguyen principalmente dos razones, la dificultad de su léxico, plagado de arcaísmos o construcciones ya en desuso, y la referencia de sus historias a un mundo periclitado. Son razones que, si pueden valer con ciertos autores u obras, no hay por qué extenderlas a todos 
los autores clásicos, puesto que, tomando algunas medidas necesarias, hay muchos fragmentos de obras que pueden presentarse a la estimativa adolescente. La Edad Media puede ser una época literaria revestida de especiales dificultades, pero algún milagro de Berceo o algunas fábulas o fragmentos de El Libro de buen amor del Arcipreste de Hita, ciertos ejemplos de El conde Lucanor y muchas canciones de amigo y romances son perfectamente inteligibles e incluso atrayentes para los adolescentes. Es cuestión primero de seleccionar la unidad del texto o fragmento del mismo y después de presentarlo debidamente adaptado o con cuantas notas o aclaraciones -nunca excesivas para no desviar la atención de lo que importa- sean necesarias para hacer llegar la historia y el mensaje al joven lector. Esto, que es de sentido común, es lo que hoy defienden quienes se ocupan del tema (Colomer, 1998; García Gual, 1998; Sotomayor, 2005 y 20I3; Arlandis, 2007; Cerrillo, 20IOa, 20IOb; Navarro, 2013, 20I6).

6. Los clásicos ayudan a la formación integral de los jóvenes lectores. Por eso también siguen siendo necesarios en la educación de hoy; nunca deberían dejar de serlo. Con su rica y profunda visión de la condición humana, un clásico es un valor añadido a la educación del joven, ya que está empezando a asomarse al mundo con ojos de adulto y necesita referentes y modelos, tanto para su maduración intelectual y humana en general como para aprender lengua. En este sentido, como se dijo en el punto anterior, no dejan de ser ejemplos de precisión y variedad léxica, de acierto y fuerza expresiva, de captación de lo real y, a la vez, de despliegue imaginativo. Es su calidad y su excelencia lo que les hace dignos de conocimiento y de estudio. Partiendo siempre de la premisa de que la lectura ha de ser placentera y adecuada a las capacidades del lector; es decir, ha de estar bien seleccionada, adaptada y motivada, tal como defienden los especialistas (Reyzábal y Tenorio, I992; Navarro, $2 \mathrm{OI} 3$ y 2OI6; Sotomayor, 2OO5 y 2OI3; Ordine, 2OI7).

Los especialistas reiteran que la lectura de un clásico en edad temprana puede dejar huella y abrir nuevos horizontes para lecturas posteriores, en la edad adulta, que han de resultar diferentes pero igualmente relevantes. Lo que sí que hay que hacer es leerlos en las mejores condiciones para saborearlos. La clave, entonces, para acercar los autores de otras épocas a las mentes de los adolescentes y los jóvenes no será otra que la de hacérselos ver como portadores de sentido. Como cercanos y comprensibles a sus gustos, intereses y necesidades. Como experiencias vivas que les hagan pensar y sentir, divertirse y soñar ${ }^{2}$.

Si es cierto que la gran potencialidad de los clásicos solo puede descubrirse en plena madurez, para llegar a ella hay que ponerles en camino ya en la etapa de formación (Sotomayor, 20I3).

\footnotetext{
${ }^{2}$ En este sentido, llaman la atención por su novedad y osadía las experiencias colectivas e interdisciplinares llevadas a cabo en la Comunidad de Murcia (Caro, 20I4).
} 


\section{La cuestión del canon}

Adjunto al tema de los clásicos no debe silenciarse la polémica sobre el canon que ha ocupado las últimas décadas. Acudimos a Sullá para la definición de este concepto. El canon, dice, "es una lista o elenco de obras consideradas valiosas y dignas por ello de ser estudiadas y comentadas" (I998: II). Las dudas, o las voces que contra los clásicos se erigen, responden a la implantación del relativismo posmodernista, aprovechado en este caso por ideologías excluyentes de los que en las universidades norteamericanas, sobre todo, están librando una feroz batalla contra la cultura que denominan blanca, machista y de clase. Contra sus razones puramente ideológicas reaccionó Harold Bloom con la publicación de un libro tan contundente como polémico. En El canon occidental (I995) opone el criterio esteticista frente a los recelos e imposiciones ideológicas de los denominados cultural studies, de raigambre marxista.

Con este enfrentamiento, el concepto de canon ha pasado a estar de moda en la teoría literaria y a suscitar no pocas discusiones. En España, quien más ha hecho por analizarlo, no solo como problema teórico sino en su formación y uso en el contexto de la literatura española, ha sido el profesor Pozuelo (I996; 2000; 2006; 2009). Su mediación en la polémica ha pretendido centrar el problema, más allá de las razones esencialistas de Bloom y de los intereses ideológicos radicales de lo que este profesor norteamericano ha bautizado como "Escuela del Resentimiento".

Con buen criterio, Pozuelo (en Pozuelo y Aradra, 2000) plantea la cuestión del canon dentro del pluralismo de los códigos culturales (Lotman) y la teoría de los polisistemas (Even-Zohar), de tal modo que, por una parte, se considere que todo canon es "histórico" y "positivo", y hay que entenderlo como algo dinámico y en continua formación, y, por otra parte, condicionado a los valores e intereses ideológicos y formativos imperantes en cada cultura y en cada época. Además, la formación del canon depende de múltiples factores o sistemas que se contrapesan e interactúan en cada momento, de tal modo que nunca se dé como algo estático, sino que se vea, más bien, como un proceso (2OOO).

El tema del canon no hace sino preguntarse por qué los clásicos son los que se dicen y cómo han llegado a esa condición. Entre los variados condicionantes del canon (que en la actualidad incluye las editoriales y su poder publicitario, los medios audiovisuales y escritos, los grupúsculos y escuelas literarias, las políticas culturales, etc.) hay que referirse primordialmente a dos: por una parte, la universidad, que acoge a los profesores y profesionales de las humanidades y la literatura, que son los que centran la atención sobre determinados autores con sus estudios y ensayos, con su dirección de colecciones de clásicos y sus participación en el consejo de editoriales. Por otra, a la institución educativa en general, que tiene carácter oficial, pues es asunto de Estado, y cursa los currículos de la enseñanza general de sus ciudadanos, en la que los expertos, como es natural, tienen su papel de asesoramiento, aunque el proyecto final sea de los gobernantes. Lo apunta Francisco Rico (I990): “Los libros que suelen considerarse `obras maestras' a menudo han 
adquirido la reputación de tales en la escuela, y en la escuela ha sido casi siempre donde se les ha otorgado la calidad de espejo y símbolo supremo de una cultura o una nación” (p. I39).

El canon, tal como hoy se concibe, no es algo único y fijado, sino algo plural, dinámico, fluctuante. Ya Azorín se adelantó a este consenso de la crítica actual al sostener en las primeras décadas del siglo XX que los clásicos evolucionan al par de la sensibilidad de las generaciones, pues son los lectores los que eligen sus lecturas, sus autores preferidos, de tal forma que bien se puede decir que un canon es la lectura que desde el presente se hace del pasado, pues en el horizonte histórico de los clásicos, "el horizonte del pasado, queda solapado y puesto al servicio del horizonte del presente" (García, 20I5: II). Pedro Salinas (I983), que con singular perspicacia ya se ocupó de este tema en la primera mitad del siglo XX, escribió estas sabias palabras al defender la existencia de un elenco selectivo o canon: "En realidad, los clásicos son los escogidos por el sufragio explícito de las generaciones y los siglos, por tribunales que nadie nombra ni a nadie obligan en verdad, pero cuya autoridad por venir de tan lejos y de tan arriba se acata gustosamente" (p. I6I). E, igualmente, opinaba que la clasificación y el concepto de clásico deben ser "cosa fluida, constantemente abierta a rectificación, a nombramientos, a cesantías, a vacaciones" (p. I6o). Lo sabía muy bien, porque la generación de poetas-profesores a la que él pertenecía, la del 27, había traído a la primera línea de la literatura española en los años anteriores a la guerra civil nada menos que a autores como Góngora y san Juan de La Cruz, hasta entonces poco frecuentados.

Ni sincrónica ni diacrónicamente hay un canon, sino muchos, que además se pueden parcelar: cánones universales, cánones nacionales, cánones de periodo o siglo, cánones de movimiento o escuela, cánones de géneros literarios, cánones temáticos... Todo depende de los criterios que se utilicen para hacer la selección que se pretende. Al fin y al cabo, el afrontamiento de los clásicos es una cuestión hermenéutica, pues hay que acudir a ellos como susceptible su mensaje de poder incorporarlo a nuestro "horizonte de expectativas". El clásico no le pide al lector que se amolde a él, sino que él, lejos de exigir una servidumbre intemporal, se ofrece como generador de sentido más allá de su tiempo, como proyección de futuro, en todo tiempo, o al menos en un presente renovado. Por tanto, un clásico es quien es capaz de mostrar una continua apertura al lector de los tiempos venideros; no es un producto cerrado y cifrado, es algo vivo, mudable, adaptable, donador de sentido en contextos diversos y cambiantes (Pozuelo, I996; Colomer, I998; Cerrillo, 20I3).

La cuestión del canon no se suscita solo en la actualidad universitaria, sino que compete a todos los grados de enseñanza y educación literaria. Es lo que se ha venido a llamar “canon pedagógico”. El profesor Pozuelo lo planteó así hace años: no es un problema estético sin más, es también una opción pedagógica (I996). La cuestión viene de largo, nada menos que desde que la historia literaria empezó a despuntar como entidad autónoma en el XIX y pasó a formar parte de las materias de enseñanza oficial del Estado con el Plan Pidal de i845. Entonces surge el canon de autores que conformarían el culturalismo nacionalista de la enseñanza burguesa. (Núñez, 2OI4). 
En las últimas décadas se han ocupado del canon pedagógico los más reconocidos especialistas en literatura infantil y juvenil. Todos ellos recalcan que un buen canon escolar tiene que estar enfocado a la formación literaria del alumno. Y esta, por otra parte, se desarrolla en la sucesión de los distintos niveles escolares, por eso es necesario que haya distintos cánones según edades y niveles, empezando desde los libros más elementales, cuando el niño todavía empieza a hablar y deletrear, a los clásicos infantiles y juveniles, hasta desembocar, ya en la enseñanza media, en los clásicos de toda la vida. (Colomer, I998; Cerrillo, 2OIOa, 2OIob y 20I3). Se habla también de “canon formativo", que es el resultado de la selección, hecha con criterios didácticos y formativos, de la combinación de una serie de cánones: el escolar, que incluye las propuestas del canon institucional, el de aula y el de literatura infantil y juvenil. Estas lecturas graduadas y sucesivas son las que van formando en el alumno su "competencia literaria ", que irá avanzando con los años (Mendoza, 2006).

Los clásicos propiamente dichos tienen su lugar en la enseñanza media, que no puede ser ajena al enfoque humanista de esta y debe sustentarse en ellos por las importantes razones antes expuestas. Cerrillo (20I3: I7) las sintetiza así:

- porque en sus historias y en sus textos está contenida buena parte de la cultura y la tradición del mundo.

- porque son modelos de escritura literaria.

- porque son una herencia dejada por nuestros antepasados.

- porque han contribuido a la formación de un imaginario cultural que ha aportado su peculiar lectura del mundo en sus diferentes épocas.

Se discute, sin embargo, hasta qué punto pueden estar y en qué grado de dificultad. También el debate surge si el acceso a los clásicos tiene que ser en sus textos originales o con adaptaciones de calidad. La selección y el tipo y modo de acceso estarían sometidos al criterio del profesor. Lo que sí se estipula entre los especialistas es que el canon de clásicos sea amplio y variado en géneros, corrientes y tendencias y sirva de estímulo a la lectura del adolescente, para que se sienta cómodo e interesado leyéndolos y no se ciegue en él la fuente de placer que en toda lectura debe experimentar. Un "canon mixto" que sepa adecuarse al contexto de los alumnos, a su edad, nivel e intereses (Colomer, 2008; Mendoza, 2OOI; Jover, 2007; Cerrillo, 2OIOa y 2OIob). 


\section{La lectura en general y los clásicos en particular}

La lectura siempre se consideró una necesidad y un lujo entre la gente culta, fruto natural de una educación recibida. Sin embargo, en los últimos tiempos la insistencia en su ejercicio como imprescindible y primordial objetivo de la escuela y de la asignatura de Lengua "se ha hecho obsesiva" (Margallo y Mata, 20I5: I79), y no les falta razón, pues las últimas leyes no han dejado de ponerla en lugar privilegiado del sistema de enseñanza. La LOGSE (г99o) fue la primera que hizo referencia explícita a la lectura. Alude a la importancia formativa de la lectura como acción personal placentera que reporta enriquecimiento comunicativo y cultural. (BOE, I4 de junio de I99I: 54). La LOE (BOE, 3 de mayo de 2006) anima a que todos los centros dispongan de una biblioteca escolar cuya dotación corra a cargo de las Administraciones educativas. La LOMCE (BOE, 9 de diciembre de 20I3) introduce la obligación de los centros educativos de contar con un proyecto curricular de etapa que incluya un plan lector, el cual debe articular las estrategias de lectura para todas las materias y dedicar media hora a la lectura en Enseñanza Primaria. Esta última, refiriéndose a la Enseñanza Secundaria, dice que la educación literaria “asume el objetivo de hacer de los escolares lectores cultos y competentes, implicados en un proceso de formación lectora que continúe a lo largo de la vida y no se ciña solamente a los años de estudio académico" (BOE, 3 de enero de 2OI5: 359).

Ya Pedro Salinas (I983: II5-200) escribió antes de mediado el siglo pasado un precioso ensayo que tituló "Defensa de la lectura" en el que habla de "educar para leer y leer para educar”. Ello se lograba poniendo al escolar en contacto con los mejores profesores de lectura, que no eran otros que los buenos libros. Y añadía: "Se aprende a leer leyendo buenas lecturas, inteligentemente dirigido en ellas, avanzando gradualmente por la difícil escala” (г983: г70). Aunque este poeta pensaba solo en la escuela, hoy día está más que comprobado que el germen del futuro lector empieza ya en brazos de la madre, oyendo las historias y cuentos de esta, o comprándole al niño los primeros libros en su más tierna edad y leyéndoselos en voz alta para que su oído y su alma vayan abriéndose al sugestivo y maravilloso encanto de las palabras que inventan historias y fabulaciones. Desde muy pronto hay que estimular la imaginación y las emociones del niño a través de la lectura (Bettelheim y Zelan, I982). La potencialidad simbólica del lenguaje, su poder para crear mundos posibles e imaginarios, se descubre ya en la primera infancia (Wells, I988).

A pesar de tanta insistencia del fomento de la lectura en la escuela y de que la escolarización gratuita es ya un bien general, no se puede decir que el objetivo de hacer de los alumnos lectores cada vez más interesados en los libros, hasta el punto de que lo tomen como hábito en su vida adulta, se esté cumpliendo. Ni en Europa ni en España los niveles de lectura logran repuntar en los últimos años, más bien parecen estancarse. Los universitarios de hoy leen menos que leyeron sus padres (Colomer, 2009). De hecho, cuando más leen los escolares es en el tramo de los 9-II años, y desciende en secundaria, pues las ocupaciones entorpecen la lectura como ocio. En secundaria lo audiovisual les 
atrae mucho más: los móviles, las redes de amigos, los videojuegos... Y, además, fuera del horario escolar suelen ocuparse en nuevas aficiones: el deporte, la música, el segundo y tercer idioma... (Murduchowicz, 2008; Lluch, 2OIO). A finales de la secundaria el nivel de lectura desciende considerablemente, para continuar haciéndolo en el bachillerato. Bien puede decirse que a más tiempo de escolarización, mayor desafección por la lectura (Latorre, 2007).

El objetivo común docente, por prescripción curricular, es fomentar el amor por la lectura en el alumno desde su misma escolarización. Los esfuerzos se hacen; sin embargo, los resultados no siempre son los deseados y el debate entre los especialistas surge a la hora de marcar los grados, los tiempos, los métodos, las exigencias...

Los factores que contribuyen a hacer que un niño se aficione a la lectura son diversos y complejos. Se puede enumerar la voluntad, la familia, el entorno sociocultural, el sistema educativo y los métodos escolares, la emoción que se siente, el azar, etc. (Cerrillo, 20IOa; Mekis, 20I6). Sí que parece que los niños a los que desde pequeños se les lee libros y aquellos en cuyos domicilios hay un alto nivel sociocultural y bibliotecas bien abastecidas se implican más en la lectura, y que en la escuela muchos otros descubren la afición, pero esta no prenderá con el mismo entusiasmo y dedicación en todos los escolares, pues hay niños que siempre se muestran reacios a leer y que la lectura no supone para ellos ningún placer. Y así, sin haber encontrado el gusto por la lectura llegan a secundaria. Y acaban secundaria lo mismo (Colomer, ı998; Cerrillo, 2007, 2OIob; Latorre, 20O7). No entraremos en consideraciones sobre si la competencia literaria es o no innata, tal como lo plantearon los teóricos del generativismo. Sí que diremos que, como sucede en otras muchas competencias en la vida, no todos nacemos con el mismo grado de inclinación y predisposición para el gusto por la literatura, y que aunque el medio y la educación cumplen un importante papel para su fomento, no lo son todo. Latorre (2007) llega a considerar que, en cualquier nivel escolar, podrán encontrarse tres tipos de lectores, cuyos porcentajes variarán según circunstancias diversas: los "lectores frecuentes", los "lectores ocasionales" y los "no lectores". Estos últimos, los pocos libros que han leído lo han hecho por obligación escolar y sin otro provecho. Y aún hay más, pues alumnos sin ningún estímulo lector acceden a las carreras de magisterio con la pretensión de ser futuros profesores y educadores (Dueñas, Tabernero, Calvo y Consejo, 20I4).

Claro que leer es algo más que leer un libro, o, en estos tiempos, no solo en libro, pues los sistemas icónicos e informáticos están generalizados, como advierte Ana DíazPlaja (2009). Esta estudiosa del tema distingue tres conceptos a la hora de describir las lecturas de los jóvenes. El primero lo llama "campo de lectura” para referirse a la diferente clase de libros según su valoración cultural y sociológica, y distingue la cultura canónica o escolar de la baja cultura, la de la calle. El segundo "forma de lectura", que sería el medio o soporte por el que llega el texto: cómic, música, videoclip, la red... El tercero, "modo de lectura", según el origen del acceso a los textos: hay uno vertical o dirigido y es el que va de profesor a alumno; y otro horizontal, que es el que nace por consejo o insinuación de un compañero. Estos tres aspectos se combinan en los jóvenes y hacen que sean más 
lectores de lo que creemos, aunque los textos estén fuera del alcance escolar, al margen de la cultura reglada y los medios y modos que en la escuela se estilan.

La escuela, naturalmente, tiene que ocuparse de incentivar la lectura en el escolar y hacerlo para su enriquecimiento y placer. Este placer lector en el que tanto se insiste debe entenderse en un doble sentido: como placer propiamente dicho, cuando el sujeto reconoce saberes previos; es decir, reconoce lo propio en lo ajeno; y como gozo, cuando descubre saberes nuevos; es decir, que descubre lo ajeno en lo propio (Caro, 20I5). Solo así el enriquecimiento o beneficio personal está asegurado.

Marina y de la Válgoma (2005) dan tres razones por las que la lectura no solo es saludable sino necesaria:

- Porque la inteligencia humana es estructuralmente lingüística y tanto sirve para comunicarse con los demás como con uno mismo. La reflexión es fundamental en el desarrollo personal y "la palabra es la gran animadora de nuestra intimidad" (p. 6o).

- Porque el fondo de nuestra cultura es lingüística y se transmite lingüísticamente. La cultura es la experiencia ancestral que el hombre ha adquirido de sí mismo a través del lenguaje, y es también la experiencia ancestral del mundo.

- Porque la convivencia es lingüística y gran parte de la comprensión del mundo se aprende de los escritores, tanto en lo que se refiere al mundo próximo o familiar, de los afectos, como al ámbito social o humano en general.

Sin embargo, como dijimos, ante los mismos métodos o estímulos, los estudiantes no reaccionan igual. Pennac (I993) explica que el verbo leer no soporta el imperativo, pero que a pesar de todo hay que impulsarle al alumno a leer. ¿Cómo? Más que exigiendo, compartiendo el profesor con él, con el alumno, su propia dicha de leer. La lectura, el placer de la lectura crece en libertad; se agosta con la imposición. Este aserto tan repetido puede ser verdad en algunos casos; en otros, no. En encuestas (Dueñas et al., 2OI4), hay quienes aducen que de adultos ellos no leen porque en la enseñanza media les hicieron leer ciertos libros contra su voluntad. Puede ser también una forma de sacudirse responsabilidades, de no admitir que nunca les gustó leer, ni con imposición ni voluntariamente. Por el contrario, en la misma encuesta hay quienes reconocen que esta imposición u obligación les hizo lectores, los libros que leyeron como ejercicio escolar les gustaron y les abrieron horizontes. Colomer (2009) aduce que sus estudios muestran que los buenos lectores valoran las lecturas impuestas o recomendadas en clase positivamente y los lectores débiles y los no lectores las detestan. Ya en 1973 lo advirtió en el breve pero incisivo Elplacer del texto Barthes (2007). Un lector -venía a decir- es aquel que se siente urgido por el deseo de leer. La cuestión está, sin duda, en dar con la tecla de los libros que están dentro de las expectativas del adolescente. A veces, es una cuestión de acertar o no acertar con los títulos. Aunque, quién sabe, quizás no sea tanto cuestión de elegir libros concretos, porque, al fin y al cabo, la experiencia lectora es una experiencia particular, 
y no hay mejor animación a la lectura para el alumno que unas clases bien impartidas, que le satisfagan y le inciten a leer por su cuenta. (Moreno, 2005: 154).

El abanico de ofertas de lectura para los jóvenes es hoy abundante, tanto que dificulta la selección. Casi todas las editoriales que trabajan los libros de texto escolares han creado su propia colección juvenil (Anaya, Santillana, Vicens Vives, SM, Bruño, Edebé, Oxford, Teide, Edelvives, Akal...), muchos de cuyos títulos son obras originales de escritores actuales que escriben en castellano y que se han especializado en esas edades (Juan Manuel Gisbert, Jordi Sierra i Fabra, Agustín Fernández Paz, Eliacer Cansino, Laura Gallego, etc.) o que, siendo reconocidos novelistas del gran público, hacen una incursión en temas juveniles (Carmen Martín Gaite, Eduardo Mendoza, José María Merino, Arturo Pérez Reverte, Bernardo Atxaga...). También ofrecen traducciones de otros idiomas y recuperan a los clásicos juveniles de siempre (Charles Dickens, Jack London, Arthur Conan Doyle, Julio Verne, Michael Ende...) La variedad de temas también es variopinta, dentro de los intereses e inquietudes adolescentes. Se prodiga la narrativa de aventuras, policíaca, fantástica, de miedo, histórica, sentimental, de iniciación a la vida, etc. No faltan las que se ocupan de los problemas y los ambientes propios de los jóvenes de hoy: la inmigración, la violencia, las drogas, las desigualdades de sexos, los ambientes estudiantiles... Un panorama riquísimo, tanto, que a veces es difícil abarcar y elegir entre oferta tan vasta, como apuntan quienes lo siguen y lo estudian (Díaz Plaja, 2009; Cerrillo, 2OIOa).

En cuanto a los clásicos hispánicos de los primeros siglos, la oferta es también variada y abundante y se presenta en ediciones muy cuidadas y con importantes auxilios pedagógicos. Suelen ser estos una buena introducción, las pertinentes notas para explicar vocabulario o dar noticias del contexto y suficientes actividades para ayudar a sacar provecho de la lectura. Tratándose de los primeros siglos, hay, además, esmeradas adaptaciones de títulos tan significativos como el Poema del Mío Cid, El Conde Lucanor, La Celestina, ElLazarillo, El Quïote y algunas de Las novelas ejemplares de Cervantes, para ayudar a los alumnos de la ESO a penetrar en unos universos que, si les puede resultar lingüísticamente dificultosos en su versión original, mantienen todo su valor humano y su fascinación imaginativa en una buena versión.

En cuanto a las adaptaciones, hay quienes las rechazan, pues piensan que el texto literario hay que respetarlo en su integridad, de modo que la lectura de un clásico solo hay que hacerla en el original cuando se esté preparado para ello. Colomer (I998) considera que esto debe suceder ya en bachillerato, época en que los alumnos deben abandonar el canon juvenil, con libros cuyos temas están escritos expresamente para ellos, y pasarse a la literatura de verdad. Sin embargo, son más quienes las defienden como un modo de ir preparando al lector para gustarlas íntegras en su momento. Así lo consideran reconocidas expertos, y alegan razones de peso (Sotomayor, 2005, 20I3; Hijosa, 2006; Navarro, 20I3, 20I6). Sotomayor (2005) define adaptación como "forma de reescritura en la que se trata de acomodar un texto a un receptor específico, a un nuevo lenguaje o a un nuevo contexto" (p. 2I ) ). Evidentemente, una adaptación implica una diferencia entre el contexto de producción y el de recepción; no obstante, reconoce que su función es de 
gran importancia en la educación en general siempre que sean de calidad. Esta estudiosa desecha el purismo a ultranza y aduce que, por el mismo criterio, habría que rechazar por engañosas una traducción o una lectura parcial, antológica, de una obra (Sotomayor, 2005, 2013).

Otros entendidos abogan también por acercar paulatinamente los clásicos a los de menos edad en pequeñas dosis, con versiones graduadas o adaptaciones adecuadas a su competencia literaria, y precisamente para que la dificultad que puedan tener para ellos no vaya en detrimento de la grata experiencia que debe ser toda lectura literaria. Navarro (2OI3) dice que es indispensable abrir las páginas de los libros de los clásicos a niños y adolescentes y que no hay otro camino para ello que la adaptación. Aduce dos razones: la primera es que si no se adaptasen tales clásicos estos dejarían de serlo y se convertirían en simples libros raros y curiosos; la otra es que la formación de los adolescentes se vería empobrecida sin ellos. Lo único que hace falta es lograr adaptaciones de calidad y que sean fieles al original. Hijosa (2006) defiende también este tipo de acercamiento de los clásicos y pondera las ventajas que tiene para favorecer su competencia literaria: no solo leerán más y mejor si el libro lo entienden y les gusta, mejorarán también sus habilidades de escritura.

Fomentar la lectura placentera y fructífera de los alumnos es, pues, una ardua tarea que tiene encomendada el profesor de Lengua castellana y Literatura, en medio de una oferta variada y diversa. No hay que olvidar que, junto a los libros que han pasado el filtro de las editoriales y que, junto a su nivel estético, están pensados para imbuirles una serie de valores, hay otros que lanzan las editoriales comerciales con el solo objetivo de vender y que más, que educarles, lo que hacen es presentarles superficialmente una serie de temas que halagan su curiosidad pero no incentivan ni su reflexión ni su maduración emocional y afectiva. Es el caso de la llamada chik lit que leen por transmisión y préstamo entre ellos (Olid, 2OO9), y a las que Lluch (2OIO) denomina “lecturas por impulso", porque a ellas se accede como a un objeto consumista más.

No hay soluciones mágicas para interesar a los jóvenes en la lectura, aunque casi todos los especialistas en el tema se atreven a dar pautas y consejos para ello. Colomer (I995) estima que la mediación del profesor ha de notarse en:

I. Poner en contacto al alumno con el texto.

2. Elegir textos atractivos que entren dentro de las expectativas de los adolescentes, y, si no, motivarlos y preparar el terreno para ello.

3. Suscitar la implicación y la respuesta de los lectores.

4. Construir el significado de manera compartida.

5. Poner el texto en contacto con otra clase de textos visuales, auditivos, etc.

Puede haber posturas maximalistas que quieran preservar la lectura como un acto supremo de libertad y en el que el hecho del acto de leer sea ya de por sí un hecho autónomo y suficiente. Serían casos como el de Pennac (I993). Es grande, sin embargo, el 
consenso que hay entre pedagogos de la lectura para fomentar esta con vistas a ir más allá del simple hecho de leer. Invitarlos a leer para que consoliden el hábito lector, y, a continuación, ayudarles a hacer una interpretación de lo leído, ayudarles a profundizar y sacar provecho de sus lecturas. Para ello puede combinarse el ofrecerles lecturas optativas, autónomas, fruto de su elección, junto a otras compartidas y guiadas (Hijosa, 2006; Margallo y Mata, 20I5).

Para terminar, citamos tres ideas en las que insisten Marina y de la Válgoma (2005):

- Es muy importante crear el hábito de la lectura, porque el hábito crea el deseo y la afición.

- Si es preciso, hay que reforzar con argumentos la razón del acto de leer, porque muchas veces se trata de eliminar prejuicios y un sistema de creencias mal fundamentadas.

- Junto a ello, es imprescindible allanar el camino para que el alumno lleve a cabo el acto de la lectura.

\section{A modo de ejemplo}

Para que el presente trabajo no quede en mera exposición teórica, añadimos tres ejemplos prácticos de cómo presentar a los alumnos textos concretos de la literatura medieval e implicarlos en su lectura e interpretación. Tenemos en cuenta las funciones que la literatura ha de cumplir en el currículum de la enseñanza secundaria (BOE, 3 de enero de $2015,35^{8)}$ :

- favorecer el conocimiento de las posibilidades expresivas de la lengua

- desarrollar la capacidad crítica y creativa del alumno

- posibilitarle el acceso a otras épocas y culturas

- ponerle ante situaciones que le ayuden a conocerse y, al mismo tiempo, enriquezcan su experiencia del mundo.

Los textos elegidos y las actividades que se proponen están pensados para alumnos de segundo y tercero de la ESO, pues valen tanto para iniciarlos en los géneros literarios como para un aprendizaje cronológico de la literatura hispana. Unos y otras irán encaminados a desarrollar en ellos tanto las capacidades lingüísticas y metalingüísticas como las afectivas y emotivas, las éticas y las estéticas.

Se puede empezar por el género narrativo para adentrarnos en un personaje histórico y literario como el Cid. Los alumnos leerán La leyenda del Cid de Agustín Sánchez Aguilar (Vicens Vives, colección Cucaña), que es una buena adaptación e integración del material literario medieval sobre este héroe. Para comprender la épica y la mentalidad de los siglos en que se dio es importante enfocar el trabajo de la postlectura con vistas a 
dilucidar el concepto de héroe, motivo mítico de todas las culturas. Los alumnos pueden definir qué es hoy un héroe, a quién se le considera tal, qué propiedades o virtudes reúne $\mathrm{y}$, una vez establecidas sus visiones, se trataría de observar si todas o algunas de ellas se ven reflejadas en el Cid cuya historia han leído.

Sugerimos para el profesor unas lecturas que le servirán para orientar el enfoque del "héroe", tema especialmente interesante para estas edades liminares entre la fantasía de la niñez y la apertura a la vida de adulto. El libro La tarea del héroe (Ariel, I98I) de Fernando Savater, que fue Premio Nacional de Ensayo, o una síntesis expuesta en su artículo "El héroe como proyecto moral", publicado en un monográfico sobre el tema en Revista de Occidente (1985), y el libro de Luis Alberto de Cuenca El héroe y sus máscaras (Mondadori, I99I). Las preguntas y actividades irán determinadas a que los alumnos entiendan la naturaleza simbólica del héroe en dos dimensiones: como seres valientes y buenos estrategas que luchan por los intereses de su comunidad en una sociedad inmersa en la guerra, y como portadores de valores humanos y virtudes morales que son significativos para la comunidad: capacidad de sacrificio, honor, lealtad, arrojo, humanidad, espíritu de justicia, mesura, religiosidad, etc.

Una vez comentado el libro desde esta perspectiva, se pueden aportar nuevos textos tomados del Cantar de Mío Cid, si bien en fragmentos adaptados y con las debidas aclaraciones léxicas y contextuales. La finalidad es que observen las diferencias entre el original y la adaptación, al tiempo que se comenta algún rasgo de estilo o se hacen deducciones sobre el carácter del héroe y la sociedad que le rodea. Para adentrarse en los romances cidianos, otra extensión de la temática que se trata, está bien leer y comentar "La jura de Santa Gadea", sobre todo porque este episodio está omitido en el Cantar. Se pueden elegir, igualmente, otros fragmentos de especial intensidad emotiva, como la petición de posada del Cid en Burgos y su negativa, con el episodio de la niña, que, además, se puede poner en relación con el poema "Castilla" de Manuel Machado para ver la creatividad de este autor tomando como pie un mínimo apunte del cantar épico. Otros episodios que suelen dar juego para estas edades son el del león que anda suelto en palacio y la relación familiar del Cid, para lo cual cabe contrastar la tristeza de la despedida en el monasterio de Cardeña y la llegada a Valencia de su mujer e hijas una vez ganada la ciudad.

Pasando al género lírico, se puede empezar con textos de la lírica popular o de tradición oral, muy apta para estas edades por ser los poemas breves y emotivos, fáciles en sus estructuras formales y, a la vez, sugerentes y llenos de simbolismo. Conviene elegir algunos de los más representativos para su lectura y de ellos ir sacando, a través de preguntas motivadas y dirigidas, los principales rasgos formales y los motivos o temas tratados. Como material auxiliar deben servir apuntes previos o la explicación teórica del libro de texto.

El segundo ejercicio sería darles otra pequeña selección (alrededor de media docena) de breves poemas de autores del siglo XX (Antonio Machado, Juan Ramón Jiménez, García Lorca, Alberti, Miguel Hernández, Blas de Otero, etc.) que siguen las pautas de la 
lírica popular. Es importante que los lean y se recreen en ellos y que escriban o digan cuál o cuáles prefieren y por qué razones. Si ya se analizaron los de la primitiva lírica, esto ya no es necesario hacerlo explícitamente, pues ellos tendrán asumidos sus rasgos, pero sí que pueden ver nuevos temas u orientaciones en la creatividad de muchos siglos después.

Y aún se puede hacer un tercer ejercicio -que también puede ser el primero, como entrada o motivación de la lectura de la lírica medieval- y es que ellos elijan una o dos canciones de actualidad que más escuchen y expliquen por qué les gusta y qué temas se trata en ellas. Es un modo de hacerles ver que la poesía popular, que también se cantaba, no hacía sino expresar los sentimientos que se repiten siempre, y lo hacía mediante textos elaborados y musicados, si bien cambian los enfoques, los estilos, los símbolos, porque las sociedades cambian en intereses, en valores, en formas de expresión, etc.

Para el género dramático podemos elegir un texto accesible como es el paso de "Las aceitunas" de Lope de Rueda. Teniendo una copia delante cada alumno, se puede leer primero en clase y luego hacer unas breves actividades para ver sus características principales: el tema, la estructura, los personajes, el uso de la lengua, etc. Hecho esto, puede darse a leer el cuento de Doña Truhana de El conde Lucanor para que relacionen uno con otro y vean cómo un mismo motivo puede presentarse de maneras distintas.

El segundo ejercicio, es observar las posibilidades de la puesta en escena del paso, pues como texto dramático que es se proyecta fuera y se convierte en espectáculo. Se pueden ver dos representaciones distintas para luego establecer diferencias de escenario o representación espacial, de decoración, de vestuario, de gestualización, etc. Recomendamos dos que se encuentran en la red: "Las aceitunas de Lope de Rueda por Compañía Resquebrajo Teatro" (7,24 minutos de duración) y "Las aceitunas de Lope de Rueda en el XIII Festival La Celestina, 28 de agosto 20II" (9, I2 minutos).

Tomando como pie el texto leído, pudiera realizarse un ejercicio de escritura. Que cada alumno eligiera uno de los personajes del paso y contase el suceso desde su punto de vista; es decir, que convirtiese el texto dramático en narración. Es efectivo acotarles un espacio para la redacción, de modo que ni hagan una síntesis descarnada ni se alarguen demasiado.

Hemos elegido tres tipos de textos literarios, pertenecientes a tres géneros distintos, con sus diversidades temáticas y formales, como ejemplo de lo que, según los principios didácticos de la educación actual, se puede presentar a los adolescentes para sacar provecho de los clásicos de nuestra literatura. 


\section{Conclusiones}

Los clásicos de los primeros siglos de la literatura castellana encierran una gran riqueza linguística, intelectual y cultural que debe aprovecharse en los cursos de secundaria, cuando los alumnos están conformando su personalidad. Son un buen antídoto contra los reclamos y distracciones que afectan a esta edad y que, lejos de la aportación ennoblecedora de las Humanidades, les habitúan a lo superficial y pasajero.

Una buena educación literaria supone la lectura gozosa de las obras más consideradas de nuestra literatura medieval y áurea -en fragmentos bien elegidos o incluso en obras enteras bien adaptadas- para que los alumnos aprendan a leer en la creación del ayer las constantes humanas de todos los tiempos y les ayude en su formación integral. El profesor es quien, desde el conocimiento de la literatura y de los alumnos, mejor puede elegir los textos de lectura e introducirles con ellos en los secretos de la escritura. El objetivo no será otro que hacer de la lectura un hábito y una compañía. 


\section{Referencias bibliográficas}

- Barthes, R. (2007). Elplacer del texto. Madrid: Siglo XXI.

- Bauman, Z. (2007) . Los retos de la educación en la modernidad líquida. Barcelona: Gedisa.

- Bettelheim, B. y Zelan, K. (I982). Aprender a leer. Barcelona: Crítica.

- Bloom, H. (1995). El canon occidental. Barcelona: Anagrama.

- Calvino, I. (1997). Por quéleer a los clásicos. Barcelona: Tusquets.

- Camarero, M. (1998). Introducción al comentario de textos. Madrid: Castalia.

- Caro, M. T. (2OI4). La educación literaria de los clásicos y su proyección interdisciplinaria para el aprendizaje basado en competencias. Educatio siglo XXI, 32/3, 31-50.

- Caro, M. T. (20I5). Fundamentación científica de la Educación literaria. En P. Guerrero y M. T. Caro (coords.), Didáctica de la Lengua y Educación literaria (pp. 26I-288). Madrid: Pirámide.

- Cerrillo, P. C. (2007) . Literatura infantil y juvenil y educación literaria. Barcelona: Octaedro.

- Cerrillo, P. C. (20IOa). Lectura, literatura y educación. México: Porrúa.

- Cerrillo, P. C. (2OIob). Lectura escolar, enseñanza de la literatura y clásicos literarios. En G. Lluch (coord.), Las lecturas de los jóvenes. Un nuevo lector para un nuevo siglo (pp. 85IO4). Barcelona: Anthropos.

- Cerrillo, P. C. (20I3). Canon literario, canon escolar y canon oculto. Quaderns de Filologia. Estudis literaris, vol. XVIII, I7-3I.

- Colomer, T. (1998). La formación del lector literario. Madrid: Fundación Sánchez Ruipérez.

- Colomer, T. (2009). Entre la normalidad y el desinterés: los hábitos lectores de los adolescentes. En T. Colomer, Lecturas adolescentes (pp. 19-58). Barcelona: Graó.

- Díaz-Plaja, A. (2009). Entre libros: la construcción de un itinerario lector propio en la adolescencia. En T. Colomer, Lecturas adolescentes (pp. Iı9-I50). Barcelona: Graó.

- Dueñas, J. D. et al. (20I4). La lectura literaria ante nuevos retos: canon y mediación en la trayectoria lectora de futuros profesores. Ocnos, II, 2I-43. 
-Eliot, T. S. (1992). Sobre poesía y poetas. Barcelona: Icaria.

- García, M. A. (20I5). Cómo enseñar a los clásicos. Fundamentos (azorinianos) para la docencia de la literatura española. Monteagudo, 2O, I35-I59.

- García Gual, C. (27-X-1998). El viaje sobre el tiempo o la lectura de los clásicos. El País, pp. 36 y $3^{8 .}$

- García Posada, M. (1982). El comentario de textos literarios. Madrid: Anaya.

- Hijosa, V. (2006). Lecturas graduadas: su importancia como recurso didáctico en educación secundaria y bachillerato. Interlingüística, I6, 579-588.

- Jover, G. (2007). Un mundo por leer. Educación, adolescentes y literatura. Barcelona: Octaedro.

- Latorre, V. (2007). Hábitos de lectura y competencia literaria al final de la ESO. Ocnos, 3 , $55^{-7} 6$.

- Lipovetsky, G. (I986). La era del vacío. Ensayos sobre el individualismo contemporáneo. Barcelona: Anagrama.

- Lipovetsky, G. (i989). El imperio de lo efímero. Barcelona: Anagrama.

- Lluch, G. (20IO). Las nuevas lecturas deslocalizadas de la escuela. En G. Lluch, Las lecturas de los jóvenes. Un nuevo lector para un nuevo siglo (pp. IO5-128). Barcelona: Anthropos.

- Margallo, A. M. y Mata J. (2015). La lectura: práctica social y formación escolar. Lectura, sociedad y escuela. En J. Mata, M. P. Núñez y J. Rienda, Didáctica de la lengua y la Literatura (pp. I79-202). Madrid: Pirámide.

- Marina, J. A. y de la Válgoma, M. (2005). La magia de leer. Barcelona: Plaza Janés.

- Mekis, C. (2OI6). La formación del lector escolar. Oportunidades desde el contorno familiar, educacional, culturaly social. Zaragoza: Prensas de la Universidad.

- Mendoza, A. (200I). El intertexto lector. El espacio de encuentro de las aportaciones del texto con las del lector. Cuenca: Universidad de Castilla-La Mancha.

- Mendoza, A. (2006). El canon formativo y la educación lecto-literaria. En A. Mendoza (coord.), Didáctica de la Lengua y la Literatura (pp. 349-378). Madrid: Pearson Educación.

- Moreno, V. (2005). Lectores competentes. Revista de Educación, no extraordinario: Sociedad lectora y educación, I53-I67. 
- Murduchowicz, R. (2008). La generación multimedia. Buenos Aires: Paidós.

- Navarro, R. (1996).¿Por qué hay que leer a los clásicos? Barcelona: Ariel.

- Navarro, R. (20I3). La salvación de los clásicos. Las adaptaciones fieles al original. Quaderns de Filologia. Estudis literaris, XVIII, 63-75.

- Navarro, R. (20I6). Las adaptaciones de los clásicos: puentes hacia islas de tesoros. Edetania, 49 (julio), I7-28.

- Núñez, G. (20I4). Las historias de la literatura y la canonización de autores y obras en el sistema educativo español. Revista de Literatura, vol. LXXVI, I5 (enero-junio), 39-55.

- Olid, I. (2005). Entre chicos y chicas. La fuerza de los estereotipos. La nueva "chik lit" para adolescentes. En T. Colomer, Lecturas adolescentes (pp. I69-I84). Barcelona: Graó.

- Ordine, N. (20I7). Clásicos para la vida. Barcelona: Acantilado.

- Pennac, D. (1983). Como una novela. Barcelona: Anagrama.

- Pozuelo, J.M. (i996). Canon, ¿estética o pedagogía? Ínsula, 6oo, 3-4.

- Pozuelo, J.M. (2006). Canon e historiografía literaria. Mil Seiscientos Dieciséis, XI, I7-28.

- Pozuelo, J.M. (2009). Razones para un canon hispánico. Signa, ı8, 87-97.

- Pozuelo, J.M. y Aradra, R. M. (2000). Teoría del canon y literatura española. Madrid: Cátedra.

- Real Decreto Ioo7/I99I de I4 de junio. BOE, 26-VI-I99I, 52-56.

- Real Decreto I631/2006 de 29 de diciembre. BOE, 5-I-2007, 730-739.

- Real Decreto IIо5/20I4 de 26 de diciembre. BOE, 3-I-20I5, I69-I87 y 357-380.

- Reyzábal, M. V. y Tenorio, P. (I992). El aprendizaje significativo de la literatura. Madrid: La Muralla.

- Rico, F. (I990). Breve biblioteca de autores españoles. Barcelona: Seix Barral.

- Salinas, P. (1983). Eldefensor. Madrid: Alianza Tres.

- Sotomayor, M. V. (2005). Literatura, sociedad, educación: Las adaptaciones literarias. Revista de Educación, n ${ }^{\circ}$ extraordinario: Sociedad lectora y educación, 2I7-238. 
- Sotomayor, M. V. (20I3). ¿Qué hacemos con los clásicos? Algunas reflexiones para los futuros docentes. Lenguaje y Textos, 38, 29-35.

- Sullà, E. (i998). El debate sobre el canon literario. En E. Sullá (comp.), El canon literario (pp. II-34). Madrid: Arco Libros.

-Wells, G. (I988). Aprender a leery a escribir. Barcelona: Laia. 